\title{
Well-to-wake analysis of ethanol-to-jet and sugar-to-jet pathways
}

\author{
Jeongwoo Han $^{1 *}$ D, Ling Tao ${ }^{2}$ and Michael Wang ${ }^{1}$
}

\begin{abstract}
Background: To reduce the environmental impacts of the aviation sector as air traffic grows steadily, the aviation industry has paid increasing attention to bio-based alternative jet fuels (AJFs), which may provide lower life-cycle petroleum consumption and greenhouse gas (GHG) emissions than petroleum jet fuel. This study presents well-towake (WTWa) results for four emerging AJFs: ethanol-to-jet (ETJ) from corn and corn stover, and sugar-to-jet (STJ) from corn stover via both biological and catalytic conversion. For the ETJ pathways, two plant designs were examined: integrated (processing corn or corn stover as feedstock) and distributed (processing ethanol as feedstock). Also, three $\mathrm{H}_{2}$ options for STJ via catalytic conversion are investigated: external $\mathrm{H}_{2}$ from natural gas (NG) steam methane reforming (SMR), in situ $\mathrm{H}_{2}$, and $\mathrm{H}_{2}$ from biomass gasification.

Results: Results demonstrate that the feedstock is a key factor in the WTWa GHG emissions of ETJ: corn- and corn stover-based ETJ are estimated to produce WTWa GHG emissions that are 16 and 73\%, respectively, less than those of petroleum jet. As for the STJ pathways, this study shows that STJ via biological conversion could generate WTWa GHG emissions 59\% below those of petroleum jet. STJ via catalytic conversion could reduce the WTWa GHG emissions by $28 \%$ with $\mathrm{H}_{2}$ from $\mathrm{NG} \mathrm{SMR} \mathrm{or} 71 \%$ with $\mathrm{H}_{2}$ from biomass gasification than those of petroleum jet. This study also examines the impacts of co-product handling methods, and shows that the WTWa GHG emissions of corn stoverbased ETJ, when estimated with a displacement method, are lower by $11 \mathrm{~g} \mathrm{CO}_{2} \mathrm{e} / \mathrm{MJ}$ than those estimated with an energy allocation method.

Conclusion: Corn- and corn stover-based ETJ as well as corn stover-based STJ show potentials to reduce WTWa GHG emissions compared to petroleum jet. Particularly, WTWa GHG emissions of STJ via catalytic conversion depend highly on the hydrogen source. On the other hand, ETJ offers unique opportunities to exploit extensive existing corn ethanol plants and infrastructure, and to provide a boost to staggering ethanol demand, which is largely being used as gasoline blendstock.
\end{abstract}

Keywords: Life-cycle analysis, Well-to-wake analysis, Ethanol-to-jet, Sugar-to-jet, Greenhouse gas emissions, Fossil fuel use, Water consumption

\section{Background}

Jet fuel consumption in the US has been estimated at 3.0 trillion MJ in 2015, accounting for $10.1 \%$ of energy supplied to the US transportation sector, and this consumption is projected to steadily increase to 3.7 trillion MJ in 2040 [1]. Greenhouse gas (GHG) emissions from jet fuel combustion in the US were 149 million ton $\mathrm{CO}_{2} \mathrm{e}$ in

\footnotetext{
*Correspondence: jhan@anl.gov

1 Systems Assessment Group, Energy Systems Division, Argonne National Laboratory, 9700 S. Cass Avenue, Argonne, IL 60439, USA

Full list of author information is available at the end of the article
}

2014, accounting for $8.5 \%$ of total GHG emissions by the US transportation sector [2]. Globally, jet fuel consumption has been estimated at 377 billion liters or 13.1 trillion MJ in 2012 [3]. Moreover, air traffic is expected to grow steadily: the US Energy Information Administration projected revenue passenger miles in the US will increase from 4.0 trillion miles in 2015 to 9.6 trillion miles in 2040 [1]. In response to growing environmental concerns, the aviation industry is exploring environmentally, economically, and socially sustainable solutions to reduce fuel consumption and GHG emissions for the sustainable growth of air traffic [4]. While fuel consumption can be 
reduced by the development and use of more efficient aircraft, shorter routing, and optimized flight management and planning, it is also beneficial to displace fossil jet fuels with low-carbon bio-based jet fuels to reduce GHG emissions significantly.

To promote bio-based jet fuel deployment, several organizations (e.g., the US Federal Aviation Administration, the US Air Force, the US Navy, the International Civil Aviation Organization, and the European Union) have committed to using bio-based jet fuels. For example, the US Department of Defense purchased about 7.6 million liters of alternative fuels between fiscal years 2007 and 2014 for testing purposes [5]. The purchased alternative fuels include largely renewable jet and diesel from hydroprocessed ester and fatty acids (HEFA) and Fischer-Tropsch jet (FTJ) along with a smaller volume of alcohol-to-jet (ATJ), synthetic iso-paraffins produced via direct sugar-to-hydrocarbon technology, and Fischer-Tropsch diesel [6]. Renewable Jet from HEFA, also known as hydroprocessed renewable jet (HRJ), is produced through hydroprocessing of fatty acids from hydrogenation of vegetable, algae, or waste oil, while FTJ is produced from gasification of natural gas (NG), coal, and biomass and with a subsequent Fischer-Tropsch synthesis. In the current ATJ process, alcohol (e.g., ethanol, methanol, or iso- or normal-butanol) is first dehydrated and converted into linear olefins via catalytic oligomerization. Then, the olefinic double-bonds are saturated via a hydrotreating process to make ATJ. For commercial aviation uses, the American Society for Testing and Materials (ASTM) International has certified HRJ, FTJ (such as Fischer-Tropsch synthetic paraffinic kerosene and FischerTropsch synthetic kerosene with aromatics), synthetic iso-paraffins produced via direct sugar-to-hydrocarbon, and butanol-to-jet technologies. Other production pathways undergoing certification processes include other ATJ pathways, pyrolysis-based hydrotreated depolymerized cellulosic jet, other sugar-to-jet (STJ) pathways, and catalytic hydrothermolysis jet [7].

The key advantages of the alternative jet fuels (AJFs) over petroleum jet fuel are potential reductions in petroleum consumption and GHG emissions, which need to be evaluated on a life-cycle basis. Several life-cycle analyses of AJFs have been published. Using HEFA production details provided by UOP, Shonnard et al. [8] and Fan et al. [9] estimated the well-to-wake (WTWa) GHG emissions associated with camelina- and pennycressbased HRJ using an energy-based allocation method, with results of 22 and $33 \mathrm{~g} \mathrm{CO}_{2} \mathrm{e} / \mathrm{MJ}$, respectively. These studies assumed little land use change (LUC) impact of these fuels because the feedstocks are rotational crops. Ukaew et al. [10] investigated soil organic carbon impacts of rapeseed cultivated in inter-year rotation with wheat (wheat-wheat-rapeseed rotation) as compared to the reference wheat-wheat-fallow rotation. They modeled the top five wheat-producing counties in ten different states in the US, and demonstrated large variations in soil organic carbon changes $(-0.22$ to $0.32 \mathrm{Mg} \mathrm{C} / \mathrm{ha} /$ year) incurred by rapeseed cultivation in rotation with wheat, depending on location and farming practices. The soil organic carbon changes resulted in direct LUC impacts estimated to range from -43 to $31 \mathrm{~g} \mathrm{CO}_{2} \mathrm{e} / \mathrm{MJ}$ HRJ. Ukaew et al. [11] further examined the impact of crop prices on LUC estimates for HRJ from canola produced in North Dakota, and showed a strong correlation between canola price and LUC. Bailis and Baka [12] estimated WTWa GHG emissions from jatropha-based HRJ to be $40 \mathrm{~g} C O 2 \mathrm{e} / \mathrm{MJ}$ without LUC, and estimated that direct LUC GHG emissions would range from -27 to $101 \mathrm{~g} \mathrm{CO}_{2} \mathrm{e} / \mathrm{MJ}$, depending on the soil type. In addition, Seber et al. [13] discussed the GHG emissions from waste oil- and tallow-based HRJ, which depend highly on the system boundary for the waste feedstock. Other studies examined the GHG emissions of HRJ from camelina, algae, and jatropha with various farming and fuel production assumptions [14, 15]. Hydrothermal liquefaction, using algae as the feedstock, has also been examined for AJF production [16, 17]. On the other hand, Skone and Harrison [18] investigated FTJ production from coal and biomass using a process engineering model. The study estimated the FTJ's WTWa GHG emissions to range from 55 to $98 \mathrm{~g} \mathrm{CO}_{2} \mathrm{e} / \mathrm{MJ}$, depending on biomass type and share, catalyst type, carbon management strategy, and co-product handling method. Lastly, the GHG emissions associated with jet fuel obtained from mallee via pyrolysis was estimated at $49 \mathrm{~g} \mathrm{CO}_{2} \mathrm{e} / \mathrm{MJ}$ [19].

Since these studies were conducted with different assumptions and life-cycle analysis (LCA) approaches, efforts were made to compare these different AJFs on a consistent basis. Stratton et al. [20] compared the GHG emissions associated with FTJ from NG, coal, and biomass and HRJ from several oil crops and algae with those from petroleum jet fuel. They showed that FTJ from biomass and HRJ from vegetable oil and algae have potentials to reduce GHG emissions up to 102 and $66 \%$, respectively, relative to petroleum jet depending on process assumptions and LUC emissions. These authors further discussed the impact of variation in several parameters and key LCA issues (e.g., co-product handling method and LUC) on the GHG emissions of FTJ and HRJ [21]. Elgowainy et al. [22] expanded the AJF options by adding pyrolysis jet fuel derived from corn stover, and updated key parameters for FTJ and HRJ as well as petroleum jet fuel. Han et al. [23] refined HRJ production process assumptions on the basis of fatty acid profiles of oil seeds, and showed that WTWa GHG emissions can be reduced 
by $41-63 \%$ (for HRJ), $68-76 \%$ (for pyrolysis jet fuel), and $89 \%$ (for FTJ from corn stover) relative to petroleum jet fuel. Agusdinata et al. [24] conducted WTWa analyses of bio-based jet fuel from non-food crops (e.g., camelina, algae, corn stover, switchgrass, and woody biomass), and projected a substantial GHG emissions reduction in 2050 under several economic and policy assumptions.

Compared to HRJ and FTJ, only a few WTWa studies on ATJ and STJ are available as summarized in Table 1. Cox et al. [25] evaluated the STJ from sugarcane molasses, and estimated its GHG emissions at $80 \mathrm{~g} \mathrm{CO}_{2} \mathrm{e} / \mathrm{MJ}$, using a system expansion method. On the other hand, Moreira et al. [26] estimated the GHG emissions of STJ from sugarcane at $8.5 \mathrm{~g} \mathrm{CO}_{2} \mathrm{e} / \mathrm{MJ}$, using a system expansion method. The large difference in the GHG emissions between these two studies stemmed from differing approaches to estimating indirect effects. Cox et al. [25] assumed that sorghum production will increase as sugarcane is used as a jet fuel feedstock, resulting in LUC GHG emissions of over $100 \mathrm{~g} \mathrm{CO}_{2} \mathrm{e} / \mathrm{MJ}$ from the increased sorghum production. Moreira et al. [26], on the other hand, used the Global Trade Analysis Project model to estimate the LUC, and reported subsequent LUC GHG emissions of $12 \mathrm{~g} \mathrm{CO}_{2} \mathrm{e} / \mathrm{MJ}$. Staples et al. [27] examined nine advanced fermentation pathways from sugarcane, corn, and switchgrass (including both ATJ and STJ), and showed that the WTWa GHG emissions of jet fuels from these three feedstocks varied significantly depending on the feedstock-to-fuel conversion routes and the co-product handling method: -27 to $20 \mathrm{~g} \mathrm{CO}_{2} \mathrm{e} / \mathrm{MJ}$ for sugarcane, 48 to $118 \mathrm{~g} \mathrm{CO}_{2} \mathrm{e} / \mathrm{MJ}$ for corn, and 12 to $90 \mathrm{~g}$ $\mathrm{CO}_{2} \mathrm{e} / \mathrm{MJ}$ for switchgrass without LUC. Additionally, they investigated the direct LUC effects for three cases (low, baseline, and high emissions), and reported estimated LUC GHG results of 20-47 $\mathrm{g} \mathrm{CO}_{2} \mathrm{e} / \mathrm{MJ}$ for sugarcane, 38-101 $\mathrm{g} \mathrm{CO}_{2} \mathrm{e} / \mathrm{MJ}$ for corn, and 1-12 $\mathrm{g} \mathrm{CO}_{2} \mathrm{e} / \mathrm{MJ}$ for switchgrass. Recently, Budsberg et al. [28] examined the WTWa GHG emissions and fossil fuel use of ATJ from poplar. They investigated two options for $\mathrm{H}_{2}$ production: NG steam methane reforming and lignin gasification resulted in 60-66 and 32-73 $\mathrm{gCO}_{2} \mathrm{e} / \mathrm{MJ}$, respectively.

Cox et al. [25] and Moreira et al. [26], however, examined only STJ produced via biological conversion from sugarcane, which is not widely available for fuel production outside Brazil. Staples et al. [27] included corn and corn stover, which are more relevant to the US biofuel industry. However, Staples et al. [27] divided the production process into four stages (pretreatment, fermentation, extraction, and upgrading), and employed process assumptions for each stage (such as efficiency, energy, and mass balances) from various literature sources to estimate energy consumption in each fuel production route rather than developing a conversion process as an integrated plant. Also, the efficiencies and process energy requirements of certain processes (such as fermentation and ETJ processes) were based on theoretical maximum and expert opinions while other processes (e.g., pretreatment) were from previous techno-economic analyses

Table 1 WTWa GHG emissions of STJs and ATJs from previous studies (numbers in the parenthesis indicates estimated ranges)

\begin{tabular}{|c|c|c|c|c|c|}
\hline References & Feedstock & Co-products & $\begin{array}{l}\text { Co-product handling } \\
\text { methods }\end{array}$ & $\begin{array}{l}\text { WTWa GHG emis- } \\
\text { sions }\left(\mathrm{g} \mathrm{CO}_{2} \mathrm{e} / \mathrm{MJ}\right)\end{array}$ & Note \\
\hline \multirow[t]{2}{*}{ Cox et al. [25] } & \multirow[t]{2}{*}{ Sugarcane } & \multirow[t]{2}{*}{ Sugar, electricity, steam } & Displacement & 80 & \multirow{2}{*}{$\begin{array}{l}\text { Including indirect impact from } \\
\text { increased sorghum production }\end{array}$} \\
\hline & & & Market value allocation & 22 & \\
\hline Moreira et al. [26] & Sugarcane & Electricity, yeast ${ }^{\mathrm{e}}$ & Displacement & 8.5 & With LUC emissions ${ }^{\mathrm{a}}\left(12 \mathrm{~g} \mathrm{CO}_{2} \mathrm{e} / \mathrm{MJ}\right)$ \\
\hline \multirow[t]{6}{*}{ Staples et al. [27] } & \multirow[t]{2}{*}{ Sugarcane } & \multirow[t]{2}{*}{ Electricity } & Displacement & $-4.9(-27$ to 2.1$)$ & \multirow[t]{2}{*}{ Without LUC ${ }^{b}$} \\
\hline & & & Market value allocation & $12.7(6.8$ to 19.7$)$ & \\
\hline & \multirow[t]{2}{*}{ Corn } & \multirow[t]{2}{*}{$\begin{array}{l}\text { Distiller dry grains with } \\
\text { solubles }\end{array}$} & Displacement & $65.6(50.1$ to 117.4$)$ & \multirow[t]{2}{*}{ Without LUCC } \\
\hline & & & Market value allocation & $62.6(47.6-117.5)$ & \\
\hline & \multirow[t]{2}{*}{ Switchgrass } & \multirow[t]{2}{*}{ Electricity } & Displacement & $37.4(11.7$ to 89.8$)$ & \multirow[t]{2}{*}{ Without LUC } \\
\hline & & & Market value allocation & 37.4 (17.3 to 89.8) & \\
\hline \multirow[t]{2}{*}{ Budsberg et al. [28] } & \multirow[t]{2}{*}{ Poplar } & \multirow[t]{2}{*}{ Electricity } & Displacement & 60 to 66 & Without LUC; $\mathrm{H}_{2}$ from NG SMR \\
\hline & & & Displacement & 32 to 73 & $\begin{array}{l}\text { Without LUC; } \mathrm{H}_{2} \text { from biomass } \\
\text { gasification }\end{array}$ \\
\hline
\end{tabular}

\footnotetext{
a LUC GHG was estimated at $12 \mathrm{~g} \mathrm{CO}_{2} \mathrm{e} / \mathrm{MJ}$

b LUC GHG was estimated at 20-47 $\mathrm{g} \mathrm{CO}_{2} \mathrm{e} / \mathrm{MJ}$

c LUC GHG was estimated at 38-101 $\mathrm{g} \mathrm{CO}_{2} \mathrm{e} / \mathrm{MJ}$

d LUC GHG was estimated at $1-12 \mathrm{~g} \mathrm{CO}_{2} \mathrm{e} / \mathrm{MJ}$

e The jet production process used in Moreira et al. [26] recovers and export yeast as a co-product
} 
(TEA) of other biofuel production (such as ethanol). Thus, assumptions (e.g., plant scale) might be inconsistent among stages and processes that might not be well-integrated. Moreover, STJ produced via catalytic conversion is yet to be investigated.

To conduct WTWa analysis on emerging ATJ and STJ from the feedstocks relevant to the US using well-integrated process assumptions, the present study incorporated the results from three TEAs into the Greenhouse gases, Regulated Emissions and Energy use in Transportation $\left(\right.$ GREET $\left.^{\circledR}\right)$ model and systematically estimated WTWa GHG emissions reductions as well as fossil fuel use and water consumption by the use of these new AJFs relative to petroleum jet fuel [29]. The three TEA studies include ethanol-to-jet (ETJ) production [30], STJ production via biological conversion [31], and STJ via catalytic conversion [32]. Note that ETJ is a subset of ATJ processes using ethanol as an intermediate. Key advantages of ETJ pathways over other ATJ or alternative fuel pathways include the large feedstock availability (both sugar/starch and lignocellulosic biomass) and the technological maturity of fuel ethanol conversion, especially with starch and sugar feedstocks. Currently in the US, ethanol is largely used as a fuel additive in E10 gasoline. The Renewable Fuels Association estimated the US ethanol production at 55.6 billion liters in 2015, while the US gasoline consumption was 553 billion liters in 2015 and is expected to be reduced in the future $[1,33]$. Thus, with the $10 \%$ "blend wall," ethanol production could potentially surpass consumption in the US E10 market, which would create opportunities for ETJ pathways.

This study presents the baseline LCA results of cornbased ETJ (using integrated and distributed plants), corn stover-based ETJ (using integrated and distributed plants), and corn stover-based STJ (via biological and catalytic conversions) as compared to conventional petroleum jet using the GREET model. The GREET model is an attributional LCA model while LUC impacts are estimated via a consequential analysis. The STJ pathway via catalytic conversion uses $\mathrm{H}_{2}$ from external source. After describing the baseline results, we assess the key drivers for the GHG reductions through sensitivity analyses that examine the influence of the following: ethanol production pathways for ETJ with a distributed ETJ production, $\mathrm{H}_{2}$ sources for STJ produced via catalytic conversion, and co-product handling methods. Also, sensitivity analyses on key parametric assumptions are provided to show the impact of these parameters on the WTWa results. Lastly, GHG emissions for different jet fuel production pathways using one metric ton of corn stover as a uniform feedstock are presented to examine the impact of liquid fuel yields and GHG intensities of AJFs on the total GHG emissions.

\section{Methods}

\section{WTWa analysis system boundary and methods}

As shown in Fig. 1, the WTWa analysis system boundary in this study includes feedstock recovery (e.g., crude recovery, corn farming and harvesting, and corn stover harvesting), feedstock transport, fuel production (e.g., petroleum refining to jet, ethanol production, ETJ production, and STJ production), fuel transportation and distribution, and aircraft fuel combustion. The fuel combustion stage is also referred to as the pump-to-wake (PTWa) stage, while the rest of the stages together (socalled the upstream stages) are the well-to-pump stage.

Two feedstocks were considered for the ETJ pathways: corn and corn stover. Also, for each feedstock, two options for plant designs were examined: integrated and distributed. An integrated ETJ plant takes corn or corn stover as a feedstock, while a distributed ETJ plant takes ethanol. In other words, in a distributed ETJ production, ethanol from ethanol plants is transported to a distributed ETJ plant. Thus, the GHG emissions of ETJ from a distributed plant depend on ethanol source, which, in turn, depends on feedstocks. In particular, corn ethanol can be produced in dry or wet mills. Recently, many dry mills have adopted corn oil (CO) extraction to produce an additional by-product ( $\mathrm{CO}$ for biodiesel production) with reduced energy consumption of distillers' grains with solubles (DGS) drying. The impact of these ethanol sources is discussed in "Impact of corn ethanol source on WTWa GHG emissions of distributed ETJ production" section.

For the STJ pathways, corn stover was assumed as a feedstock. Note that the TEA studies, from which this study derives conversion process energy use, assumed a blended cellulosic biomass feedstock consisting of multipass harvested corn stover, single-pass harvested corn stover, and switchgrass. The present study assumed that the processes consume the same amount of energy if a single corn stover feedstock rather than a blended feedstock is used. It is important to note that feedstock characteristics (such as chemical compositions and ash and mineral contents) could affect product yields, energy/ chemical inputs, and pretreatment requirements [34]. The impacts of these parametric assumptions on WTWa results are discussed by conducting a sensitivity analysis. It needs to be noted that STJ produced via catalytic conversion consumes a large amount of hydrogen. Thus, the source of hydrogen could substantially affect the GHG emissions associated with STJ. In order to assess the impact of hydrogen source, three hydrogen sourcing options-external $\mathrm{H}_{2}$ from NG steam methane reforming (SMR), in situ $\mathrm{H}_{2}$ from reforming of a fraction of the biomass hydrolysate, and internal $\mathrm{H}_{2}$ via biomass gasification-were examined. 


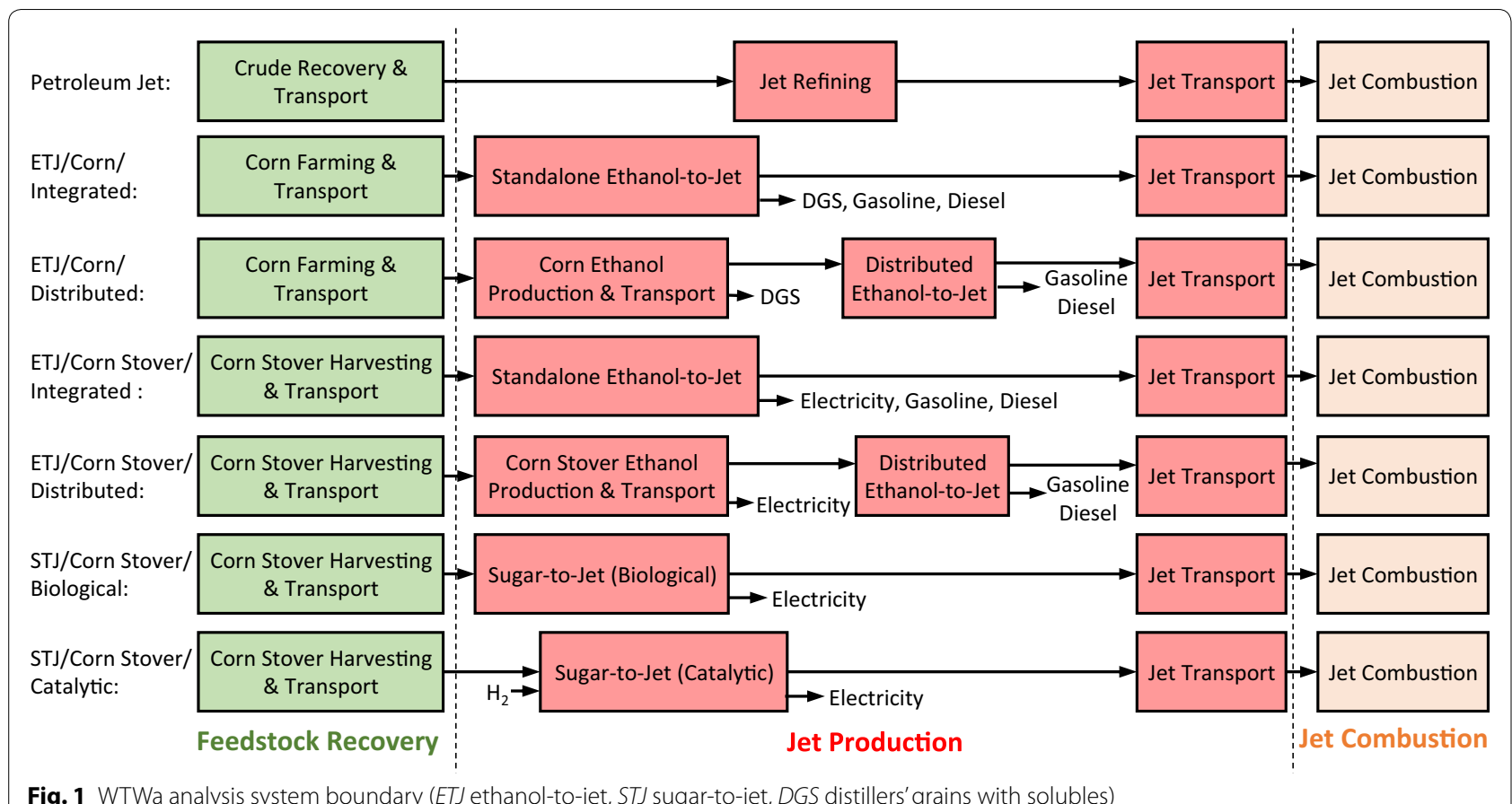

These ETJ and STJ pathways produce several co-products. In the ETJ pathway, the corn ethanol process coproduces DGS and CO, while the corn stover ethanol and the STJ processes co-produce electricity. Also, the ETJ and STJ processes co-produce a range of liquid hydrocarbon fuels, including jet. Therefore, the co-product handling method could affect the WTWa analysis results substantially [35]. Two methods are widely used to handle co-products: displacement and allocation methods. In a displacement method, all energy and emission burdens are allocated to the main product, while the energy and emissions of producing the otherwise displaced products are taken as credits for the main products. On the other hand, an allocation method allocates the energy and emission burdens of a pathway among the products by their output shares. An appropriate choice of allocation basis is important for allocation methods. Among various allocation metrics (e.g., energy, mass, and market value), energy is often used among energy products.

This study used a hybrid approach to handle various products from different processes: a displacement method was applied for electricity and DGS while an energy allocation method was used among the hydrocarbon fuels from the ETJ and STJ processes (e.g., gasoline, jet, and diesel). This study assumed that co-produced electricity would displace the US average electricity and the US average animal meal, respectively. A displacement method was selected for DGS since an allocation may not be reliable for DGS due to the difference in the types of products (meal for nutrition vs. fuel for energy). Both allocation and displacement methods are widely used in handling electricity. This study selected a displacement method as a default method because the characteristics of electricity (e.g., value, energy form) are relatively different from those of the other hydrocarbon fuels. Also, the impacts of using an energy allocation method to estimate the WTWa GHG emissions of the AJFs from corn stover (co-producing electricity) are also presented in "Impact of co-product handling method on WTWa GHG emissions of corn stover-based ETJ and STJ" section. Among the hydrocarbon fuels produced by the ETJ and STJ processes (e.g., gasoline, jet, and diesel), on the other hand, a displacement method may not be applicable because a large portion of output can be gasoline and diesel, which could result in distorted results when jet is considered as a co-product. Thus, an energy allocation was selected. Finally, $\mathrm{CO}$ was handled by a process-based method, where all energy and emission burdens during ethanol production except for those associated with $\mathrm{CO}$ recovery were allocated to ethanol [36].

The functional unit is an important factor in LCA. This study presents the results in two functional units: an energy functional unit (MJ of jet fuel) and a resource function unit (ton of corn stover). The energy functional unit is appropriate to compare compatible fuels from different sources and to show the impacts of displacing a conventional fuel with alternative fuels (ETJ and ST) vs. conventional jet). On the other hand, the resource 
functional unit compares different production pathways from the same source, which can address the resource utilization issue.

\section{Corn farming, corn stover collection, and ethanol production}

Feedstocks for ETJ and STJ in this study include corn and corn stover as well as ethanol from these feedstocks, whose key WTWa parameters are summarized in Table 2. The key parameters are based mainly on the analysis by Wang et al. [37] and subsequent updates on fertilizer applications from the latest survey of corn farming by the US Department of Agriculture (USDA) [38], corn ethanol production process updates by Mueller and Kwik [39], and the implementation of CO extraction in dry milling corn ethanol plants examined by Wang et al. [36]. In the corn stover collection stage, we assume that the supplemental fertilizer is applied to replace the nutrients in the harvested corn stover. The water consumption for corn farming includes only anthropogenic water consumption, which is the irrigation withdrawal minus the irrigation runoff [40]. We assume that corn stover does not consume water since irrigation is mainly for corn farming not for corn stover harvesting. Also, the water consumption for the ethanol production is the net of water withdrawal minus treated water returned to the same withdrawal source.

A key issue in biofuel LCA is the impact of LUC. Especially, the LUC-related GHG emissions have been extensively discussed and evaluated since they were first estimated by Searchinger et al. [41]. While the improvements in LUC modeling and assumptions have generally lowered the estimates on LUC-related GHG emissions from the results by Searchinger et al. [41], notable variation exists among recent studies depending on LUC models, scenarios, and assumptions (see Additional file 1: Figure A1). Since the LUC-related GHG emissions were not the main focus of this study, this study employed the LUC GHG emissions by Qin et al. [42, 43], which documented detailed modeling of LUC and associated GHG emissions of ethanol pathways, including tillage (i.e., conventional, reduced, and no tillage), corn stover removal (i.e., at 0,30 , and $60 \%$ removal rates), and organic matter input techniques (i.e., cover crop and manure application). As a baseline assumption, this study used 8 and $-0.7 \mathrm{~g} \mathrm{CO}_{2} / \mathrm{MJ}$ ethanol for the LUC impacts of corn and corn stover ethanol, respectively, assuming conventional tillage, $30 \%$ corn stover removal, and no organic

Table 2 Key WTWa parameters for corn and corn stover ethanol pathways

\begin{tabular}{|c|c|c|c|c|}
\hline \multicolumn{2}{|l|}{ Parameter (unit) } & \multicolumn{2}{|l|}{ Corn } & \multirow[t]{2}{*}{ Corn stover } \\
\hline \multicolumn{4}{|c|}{ Corn farming/corn stover collection (per dry ton of corn or corn stover, except as noted) } & \\
\hline Direct energy use (MJ) & & $466^{\mathrm{a}}$ & & $224^{b}$ \\
\hline N fertilizer application (kg) & & $19.4^{\mathrm{b}}$ & & $7.72^{\mathrm{b}}$ \\
\hline P fertilizer application (kg) & & $6.70^{\mathrm{b}}$ & & $2.20^{\mathrm{a}}$ \\
\hline K fertilizer application (kg) & & $6.95^{\mathrm{b}}$ & & $13.2^{\mathrm{a}}$ \\
\hline Limestone application (kg) & & $52.8^{\mathrm{a}}$ & & \\
\hline $\mathrm{N}_{2} \mathrm{O}$ conversion rate of $\mathrm{N}$ fertilizer (\%) & & $1.525^{\mathrm{a}}$ & & \\
\hline Water consumption $(\mathrm{kL})$ & & $25.4^{c}$ & & $0^{c}$ \\
\hline Parameter (unit) & Dry mill w/o CO extraction & Dry mill w/CO extraction & Wet mill & Corn stover \\
\hline \multicolumn{5}{|l|}{ Corn/corn stover ethanol production } \\
\hline Ethanol yield (L/dry ton of corn or corn stover) & $486^{\mathrm{b}}$ & $471^{b}$ & $496^{b}$ & $375^{\mathrm{a}}$ \\
\hline Ethanol plant fossil energy use (MJ/L of ethanol) & $7.49^{\mathrm{a}}$ & $7.36^{\mathrm{b}}$ & $13.2^{\mathrm{a}}$ & \\
\hline Water consumption ( $\mathrm{L} / \mathrm{L}$ of ethanol) & $2.7^{c}$ & $2.7^{c}$ & $3.92^{c}$ & $5.35^{c}$ \\
\hline DGS yield (dry kg/L of ethanol) & $0.675^{\mathrm{a}}$ & $0.646^{b}$ & & \\
\hline Corn gluten meal yield (dry kg/L of ethanol) & & & $0.147^{\mathrm{a}}$ & \\
\hline Corn gluten feed yield (dry kg/L of ethanol) & & & $0.632^{\mathrm{a}}$ & \\
\hline CO yield (dry kg/L of ethanol) & & $0.023^{b}$ & $0.117^{\mathrm{a}}$ & \\
\hline Electricity yield (kWh/dry ton of corn stover) & & & & $226^{a}$ \\
\hline Enzyme use (g/dry kg of corn or corn stover) & $1.04^{\mathrm{a}}$ & $1.04^{\mathrm{b}}$ & $1.04^{\mathrm{a}}$ & $15.5^{\mathrm{a}}$ \\
\hline Yeast use (g/dry kg of corn or corn stover) & $0.36^{\mathrm{a}}$ & $0.36^{\mathrm{b}}$ & $0.36^{\mathrm{a}}$ & $2.49^{a}$ \\
\hline Corn ethanol shares (\%) & $18^{\mathrm{b}}$ & $73^{b}$ & $9^{b}$ & \\
\hline
\end{tabular}

\footnotetext{
a Based on Wang et al. [37]

${ }^{\text {b }}$ Based on Wang et al. [36]

c Based on Lampert et al. [40]
} 
matter input techniques. Acknowledging the variations in the LUC impact, this study also conducted a sensitivity analysis using the ranges of the LUC emissions estimated by Qin et al. [42]: 5 to 17 and -1.4 to $-0.6 \mathrm{~g} \mathrm{CO}_{2} \mathrm{e} / \mathrm{MJ}$ for corn and corn stover ethanol, respectively. Note that these ranges do not represent parametric uncertainty rather sensitivity around different scenarios (e.g., tillage types, soil depth, and soil carbon database).

\section{ETJ production}

The first step in producing "drop-in" bio-jet fuel from ethanol is to remove the oxygen from the ethanol molecules via a catalytic dehydration process, producing ethylene. Then, ethylene is turned into linear or non-linear (branched) $\alpha$-olefins through the catalytic oligomerization process. Depending on the oligomerization reaction chemistry (operating conditions and catalysts), the $\alpha$-olefin produces a hydrocarbon distribution of $\mathrm{C}_{4}$ to $\mathrm{C}_{32}$. Because olefins are only allowed in limited quantities in jet fuel, the last upgrading step is to hydrogenate the $\alpha$-olefins to produce paraffins. Then, a hydroisomerization step can be applied optionally to convert normal paraffin to their isomers. Although the $\mathrm{C}_{9}-\mathrm{C}_{16}$ alkanes distilled from the hydrogenated paraffins are suitable for jet fuels, key specifications for fuel properties should be used to verify whether the produced jet blendstock meets ASTM or other standards. These three upgrading steps (alcohol dehydration, olefin oligomerization, and $\alpha$-olefin hydrogenation) are well-known industrial technologies and have been used for years at commercial scales. However, these processes have not been integrated into existing biorefineries to produce jet fuel. This integration may include either retrofitting existing dry mill plants to convert alcohols to jet fuel on site, or building dedicated plants that produce jet blendstocks via alcohol intermediates.

Table 3 summarizes the parametric assumptions for ETJ production processes, which are based on the TEA conducted by Wang et al. [30] on upgrading the biomassderived ETJ blendstocks. The TEA was conducted for integrated plants at the scale of 2,000 dry metric tons of feedstock (corn or corn stover) per day. While the biochemical cellulosic ethanol model of Humbird et al. [44] was used for the front-end process of the corn stover ETJ model, the USDA corn grain dry mill model was used as the front-end process of the dry-mill-to-alcohol process [45]. Since the USDA's corn dry mill model was developed, corn ethanol production processes have undergone technological advancements, and several studies on corn ethanol production processes reflect recent corn ethanol production trends [36, 37, 46-50]. In order to use corn ethanol production parameters reflective of current
Table 3 Parametric assumptions for ETJ fuel production processes

\begin{tabular}{llll}
\hline Feedstock & \multicolumn{2}{l}{ ETJ_integrated } & ETJ_distributed \\
\cline { 2 - 3 } & Corn & Corn stover & Ethanol \\
\hline $\begin{array}{l}\text { Jet fuel yield (MJ jet/kg feed- } \\
\text { stock) }\end{array}$ & 6.78 & 4.71 & 18.1 \\
Natural gas use (kJ/MJ jet) & 439 & - & - \\
Hydrogen use (kJ/MJ jet) & 81.3 & 80.9 & 80.9 \\
Electricity use (Wh/MJ jet) & 27.3 & - & 9.3 \\
Yeast use (g/MJ jet) & 0.051 & - & - \\
Enzyme and chemical use & 1.67 & 26.2 & - \\
$\quad$ (g/MJ jet) & & & \\
Catalyst use (g/MJ jet) & 0.094 & 0.107 & 0.107 \\
Water use (L/L jet) & 8.5 & 13.5 & 1.9 \\
Gasoline yield (kJ/MJ jet) & 210 & 212 & 212 \\
Diesel yield (kJ/MJ jet) & 113 & 115 & 115 \\
DGS yield (dry g/MJ jet) & 57 & - & - \\
Electricity yield (Wh/MJ jet) & - & 32 & - \\
\hline
\end{tabular}

technology, the back-end ETJ process for converting ethanol-to-jet fuel was modeled separately from the integrated ETJ process. The back-end process includes ethanol dehydration, oligomerization, hydrotreating, and product fractionation, whose parametric assumptions are shown in the last column of Table 3.

\section{STJ production}

This study is based on two TEA studies on STJ conversion processes, which addressed the biological and catalytic conversion routes [31, 32]. In the biological conversion route, biomass feedstock is first processed in an alkaline deacetylation step to solubilize and remove acetate and other non-fermentable components, and treated with dilute sulfuric acid catalyst to liberate the hemicellulose sugars and break down the biomass for enzymatic hydrolysis. Ammonia is then added to the whole pretreated slurry to raise its $\mathrm{pH}$ for enzymatic hydrolysis. The hydrolyzed slurry is then filtered to remove insoluble solids (namely, lignin). The solids fraction exiting the filter is combusted to produce process heat and electricity. The remaining soluble sugar stream is split into a small fraction that is sent directly to the fed-batch bioreactors to initiate conversion and a larger fraction that is concentrated in evaporators to concentrate the sugar components. The concentrated sugar slurry from the evaporators is cooled and inoculated with the generic bioconversion microorganism under aerobic reactor conditions. Once conversion is completed, most of the cellulose and xylose are converted to free fatty acids (FFAs). Then, the FFA product is recovered via decantation and 
centrifugation, and hydrotreated to produce hydrocarbon fuels. In the original TEA, the primary product is a diesel-range paraffinic product suitable as a diesel blendstock. For ASTM-certified jet fuel production, the dieselrange paraffinic product needs to be hydroprocessed to saturate double-bonds. Thus, the process engineering model was adjusted to produce a jet fuel blendstock. The adjusted parametric assumptions for STJ production processes via a biological route are presented in Table 4.

In the catalytic conversion route, biomass feedstock is processed by pretreatment and enzymatic hydrolysis steps similar to those of the biological conversion route. The glucose and other sugars from the hydrolysate, however, are then filtered to remove insoluble solids, concentrated by evaporation, and purified by microfiltration and ion exchange prior to catalytic upgrading, which consists of four stages: hydrogenation, aqueous-phase reforming, condensation and oligomerization, and hydrotreating. In each stage, hydrogen is required to the reactors, which operate at varying process conditions and have varying catalyst composition. The goal of these successive catalytic steps is to remove oxygen or "de-functionalize" carbohydrates and other carbon components and oligomerizes them to primarily diesel-range hydrocarbons. All four stages in catalytic upgrading consume a large amount of hydrogen. Davis et al. [32] investigated three hydrogen sources: external $\mathrm{H}_{2}$ from NG SMR, in situ $\mathrm{H}_{2}$ produced by reforming a fraction of biomass hydrolysate, and internal $\mathrm{H}_{2}$ produced by biomass gasification. Table 4 presents the parametric assumptions for STJ fuel production processes via the catalytic conversion route with three different hydrogen sources. Note that the internal hydrogen production reduces jet fuel production significantly because a fraction of biomass or its derivatives is used for hydrogen production rather than jet fuel production. It also should be noted that this LCA study did not make any modifications to the sugar catalytic upgrading TEA model or its associated cost results in Davis et al. [32].

\section{Crude oil recovery and petroleum jet fuel production}

The system boundary of petroleum jet fuel includes crude oil recovery and transport, and jet fuel refining, transportation, distribution, and combustion. More than half of total crude oil refined in the US refining sector in 2015 (54\%) was produced domestically [1]. The foreign sources of crude include Canada (18\%), Middle East (12\%), Mexico (5\%), Latin America (9\%), and other regions (2\%). Among them, Canadian crude consists of conventional crude and crude from oil sands, accounting for 10 and $8 \%$, respectively, of the total crude supply to US refineries. Note that the oil sands' share of the crude mix is an important WTWa analysis parameter because of the high GHG intensity of oil sands compared to conventional oil. Cai et al. [51] investigated the GHG intensities of oil sands products from four different production technologies, including the GHG emissions from land disturbance associated with oil sands recovery. Another crude source that has recently gained significant importance in the US is shale oil. The share of shale oil production as a fraction of the total crude production in the US has increased from 14\% in 2010 to $48 \%$ in 2015 [52]. The present study estimated the energy intensity and GHG emissions of shale oil using the parameters for shale oil recovery reported by Brandt et al. [53] and Ghandi et al. [54] for the Bakken and Eagle Ford plays, respectively, while the conventional crude recovery parameters are based on those of Burnham et al. [55].

The present study used the energy consumption of jet fuel production estimated by Elgowainy et al. [56], who investigated 43 large US refineries (each with a refining capacity greater than 100,000 barrels per day) using a linear programing model. The 43 refineries represented $70 \%$ of the total US refining capacity and covered a wide range of crude sources/quality, product slates, and refinery complexity. The linear programing model generated the volumetric and mass flow rates as well as the utility consumptions of individual process units in the refineries, which were used to estimate the energy consumption

Table 4 Parametric assumptions for STJ fuel production processes

\begin{tabular}{|c|c|c|c|c|}
\hline & \multirow[t]{2}{*}{ Biological [31] } & \multicolumn{3}{|l|}{ Catalytic [32] } \\
\hline & & External $\mathrm{H}_{2}$ & In situ $\mathrm{H}_{2}$ & Gasification $\mathrm{H}_{2}$ \\
\hline Jet fuel yield (MJ jet/kg corn stover) & 4.42 & 8.39 & 4.85 & 5.60 \\
\hline Hydrogen use (kJ/MJ jet) & 123 & 528 & - & - \\
\hline Electricity use (Wh/MJ jet) & - & - & 1.81 & - \\
\hline Enzyme and chemical use (g/MJ jet) & 15.9 & 8.48 & 14.7 & 9.45 \\
\hline Catalyst use (g/MJ jet) & - & 0.0034 & 0.0040 & 0.0036 \\
\hline Water use (L/MJ jet) & 15.9 & 6.1 & 10.2 & 11.9 \\
\hline Electricity yield (Wh/MJ jet) & 22.3 & 12.6 & - & 2.8 \\
\hline
\end{tabular}


for each process unit. The energy consumptions of individual process units, then, were allocated to intermediate products of the unit by their energy content in order to estimate the energy intensity of the intermediate products. By estimating the energy intensity of all streams and aggregating them for the streams that make various final products, the product-specific efficiency of petroleum products was estimated. Table 5 provides the process fuel use for jet fuel production estimated by Elgowainy et al. [56].

\section{Results}

Figure 2 presents the WTWa GHG emissions of four ETJ and two STJ pathways compared to petroleum jet. The petroleum jet generates WTWa GHG emissions of $85 \mathrm{~g} \mathrm{CO}_{2} \mathrm{e} / \mathrm{MJ}$. The four ETJ pathways include ETJ from corn using integrated and distributed plants (denoted as ETJ/Corn/Integrated and ETJ/Corn/Distributed, respectively) and ETJ from corn stover using integrated and distributed plants (denoted as ETJ/Stover/Integrated and ETJ/Stover/Distributed, respectively). The two STJ pathways include STJ from corn stover using biological and catalytic conversion routes. For the catalytic conversion route, $\mathrm{H}_{2}$ is assumed to be produced externally using NG SMR. The lower and upper ends of the error bars in the figure represent the 10th and 90th percentiles of the resulting distributions from Monte Carlo simulations. The GREET model maintains 887 parameters with distribution functions defined. Among them, the distribution function definition of 27 key parameters for the ETJ and STJ pathways are provided in Additional file 1: Table A1. Note that the conversion process assumptions are point estimates without distributions. The resulting distributions are caused by the variations in the upstream stages (e.g., corn farming, corn stover harvesting, and process fuel, chemical, and enzyme production).

The WTWa emissions of each pathway are the sum of the GHG emissions from feedstock recovery, jet production, and jet combustion, and the credits from conventional product displacement and biogenic $\mathrm{CO}_{2}$ in fuel as well as LUC emissions. Figure 1 illustrates what

Table 5 Refinery process fuel use for major fuel products $\left(\mathbf{k J}_{\text {process fuel }} / \mathbf{M J}_{\text {fuel product }}\right)$

\begin{tabular}{|c|c|c|c|c|c|}
\hline \multicolumn{4}{|c|}{ Purchased fuels } & \multicolumn{2}{|c|}{ Internally produced fuels } \\
\hline NG-SMR & $\begin{array}{l}\text { NG- } \\
\text { combus- } \\
\text { tion }\end{array}$ & Electricity & $\mathrm{H}_{2}$ & $\begin{array}{l}\text { Fuel gas } \\
\text { combustion }\end{array}$ & $\begin{array}{l}\text { Catalytic } \\
\text { coke com- } \\
\text { bustion } \\
\text { in fluid } \\
\text { catalytic } \\
\text { cracking }\end{array}$ \\
\hline 5.5 & 19 & 1.6 & 4.3 & 13 & 2.7 \\
\hline
\end{tabular}

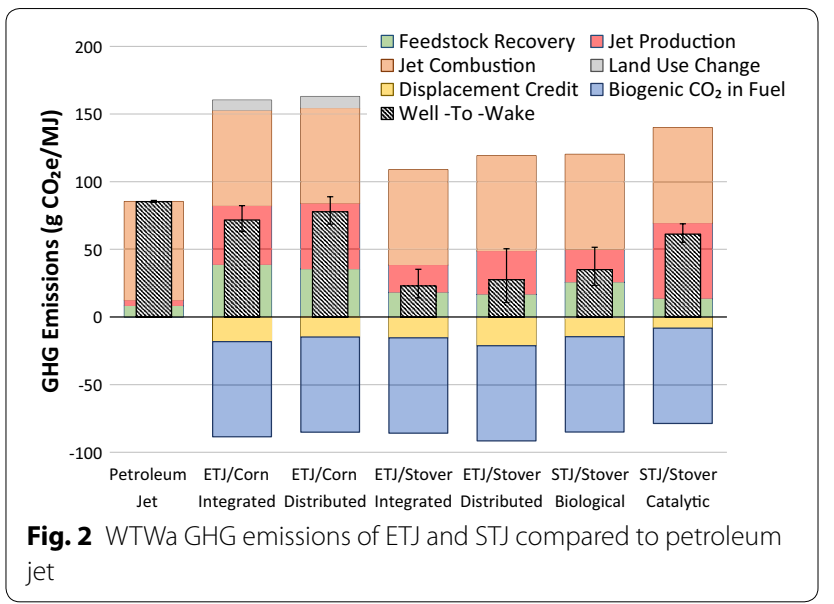

the feedstock recovery, the jet production, and the jet combustion in Fig. 2 include. As explained in "WTWa analysis system boundary and methods" section, the displacement credits are the avoided GHG emissions by displacing the conventional products (animal feeds and US average electricity) with the co-products from the pathways (DGS and electricity). The biogenic $\mathrm{CO}_{2}$ in fuel denotes the amount of $\mathrm{CO}_{2}$ absorbed during biomass growth that is ended up in fuel and combusted. Since we assumed that all carbon in fuel is derived from biomass and carbon in biomass is carbon neutral, the size of the biogenic $\mathrm{CO}_{2}$ in fuel is almost identical to that of jet combustion, which almost cancel out each other. It should be noted that a carbon neutrality assumption for biomass with short carbon cycles (e.g., annual crops) is generally agreed while that with long carbon cycles (e.g., woody biomass) is debatable.

The WTWa GHG emissions of corn-based ETJ are estimated at 72 and $78 \mathrm{~g} \mathrm{CO}_{2} \mathrm{e} / \mathrm{MJ}$ for integrated and distributed plants, respectively, while the GHG emissions of corn stover-based ETJ are 23 and $28 \mathrm{~g} \mathrm{CO}_{2} \mathrm{e} / \mathrm{MJ}$ for integrated and distributed plants, respectively. The large GHG emissions of corn-based ETJ are caused by the high GHG intensity of corn farming and corn ethanol production as well as LUC. Corn farming consumes a large amount of fertilizer, especially nitrogen fertilizer. Nitrogen fertilizer production is highly energy- and GHGintensive and generates a significant amount of $\mathrm{N}_{2} \mathrm{O}$ emission once it is applied on farm fields. Corn ethanol production is also quite energy- and GHG-intensive, consuming a significant amount of process fuels (mainly NG). Note that there are some options to reduce GHG emissions of corn ethanol, which can be applied to the corn-based ETJ pathways: (1) replacement of NG with biogas in ethanol plants and (2) integrated corn and corn stover ethanol production analyzed in Canter at el. [50]. 
On the other hand, corn stover harvesting requires only a small amount of fertilizers for supplementing nutrient losses from stover removal. Also, cellulosic ethanol production generates energy (heat and electricity) from lignin combustion beyond process requirements; excess electricity is exported to the grid. Feedstocks themselves vary significantly in their GHG intensities. Therefore, the feedstock needs to be clearly defined when the GHG emissions of ETJ are calculated. The conversion process used in the corn stover-based ETJ is similar to the low case of the switchgrass advanced fermentation pathway in Staples et al. [27], which showed $11.7 \mathrm{~g} \mathrm{CO}_{2} \mathrm{e} / \mathrm{MJ}$ of GHG intensity. A main driver of the lower GHG emissions estimated in Staples et al. [27] than estimates in this study is the feedstock and process fuel consumptions: Staples et al. [27] assumed about 70\% lower feedstock and process fuel consumptions for the conversion process than this study.

The integrated cases of ETJ generate about $5-6 \mathrm{~g} \mathrm{CO}_{2} \mathrm{e} /$ MJ lower GHG emissions than the distributed cases of ETJ because of less stringent ethanol feedstock quality and heat integration. The distributed plant is assumed to take market ethanol with moisture content less than $1 \%$ [57]. On the other hand, the ethanol feedstock in the integrated plant can contain $7.5 \%$ water, which can reduce energy consumed in distillation in ethanol production. Also, the integrated plant allows better heat integration between the ethanol and ETJ plants. Note that the removal of ethanol transport in the integrated production did not affect the GHG emissions of ETJ greatly, since its impact was offset by the longer transportation and distribution distance of ETJ from the ETJ plant to consumption.

The WTWa GHG emissions of corn stover-based STJ produced via biological and catalytic conversion are estimated at 35 and $61 \mathrm{~g} \mathrm{CO}_{2} \mathrm{e} / \mathrm{MJ}$, respectively. The large WTWa GHG emissions of STJ via catalytic conversion result from consumption of a large amount of $\mathrm{H}_{2}$. "Impact of $\mathrm{H}_{2}$ source on WTWa GHG emissions of STJ via catalytic conversion" section discusses the impact of $\mathrm{H}_{2}$ source on the WTWa GHG emissions of STJ via catalytic conversion. The conversion processes used in the corn stover-based STJ via biological and catalytic conversion are similar to the base case of the switchgrass advanced fermentation pathway in Staples et al. [27] and the STJ pathway in Budsberg et al. [28]. The GHG emissions of the two pathways in these previous studies are 37.4 and $66 \mathrm{~g} \mathrm{CO}_{2} \mathrm{e} / \mathrm{MJ}$ of GHG intensity, respectively, similar to this study's estimates.

As presented in Fig. 3, the WTWa fossil fuel use, the sum of coal, NG, and petroleum, shows a similar trend to the WTWa GHG emissions shown in Fig. 2. A similar trend results from the fact that the majority of GHG

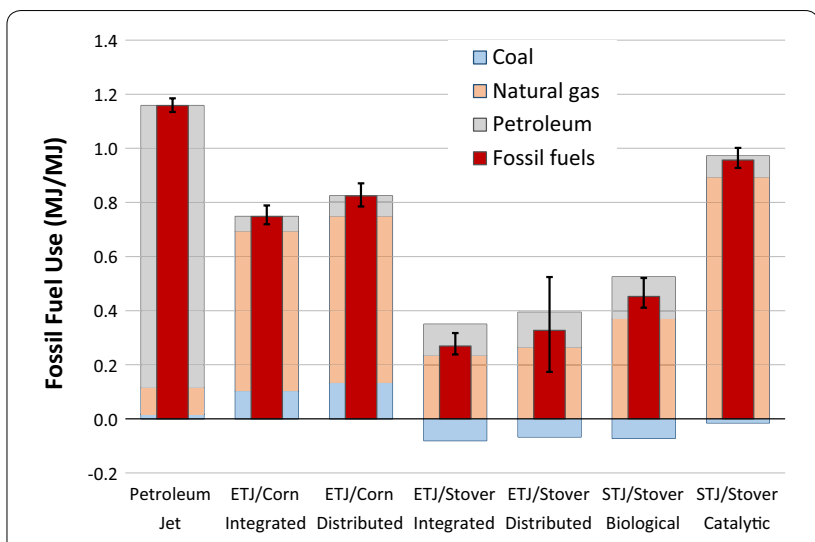

Fig. 3 WTWa fossil fuel use of ETJ and STJ compared to petroleum jet

emissions is $\mathrm{CO}_{2}$ from combustion of fossil fuels. However, the trend is not completely linear because of other emissions (most notably, $\mathrm{N}_{2} \mathrm{O}$ emissions from $\mathrm{N}$ fertilizers and biomass). Compared to the petroleum jet $(1.16 \mathrm{MJ} / \mathrm{MJ})$, the fossil fuel use of corn-based ETJ is estimated at 0.75 and $0.82 \mathrm{MJ} / \mathrm{MJ}$ for integrated and distributed plants, respectively, while the fossil fuel use of corn stover-based ETJ is 0.27 and $0.33 \mathrm{MJ} / \mathrm{MJ}$ for integrated and distributed plants, respectively. Also, the fossil fuel use of corn stover-based STJ produced via biological and catalytic conversion are estimated at 0.45 and $0.96 \mathrm{MJ} /$ MJ, respectively. NG consumption accounts for the largest share of the fossil fuel use of the ETJ and STJ pathways. Especially, corn ethanol production for corn-based ETJ and $\mathrm{H}_{2}$ consumption for STJ via catalytic conversion account for the largest NG consumption. The negative coal use for the corn stover-based ETJ and STJ pathways results from the displacement of the US average generation mix, $41 \%$ of which is from coal.

Figure 4 provides the WTWa water consumption of ETJ and STJ compared to petroleum jet. For the cornbased ETJ pathways, the irrigation for corn farming is the major water consumption, accounting for approximately 3.4 L/MJ. Note that the corn-based ETJ pathways also have large water credits due to animal feed displacement. Corn stover-based ETJ from integrated and distributed plants consumes 0.83 and $0.88 \mathrm{~L}$ of water per MJ, respectively, while STJ via biological conversion consumes 1.2 and $0.40 \mathrm{~L}$ of water per MJ, respectively. For the corn stover-based ETJ and STJ pathways, water is consumed largely for enzyme production and jet fuel production.

\section{Discussion}

Impact of corn ethanol source on WTWa GHG emissions of distributed ETJ production

Currently, 208 ethanol plants in the US receive corn as a feedstock [33]. While each ethanol plant is unique, they can be categorized into three groups: dry mills with $\mathrm{CO}$ 


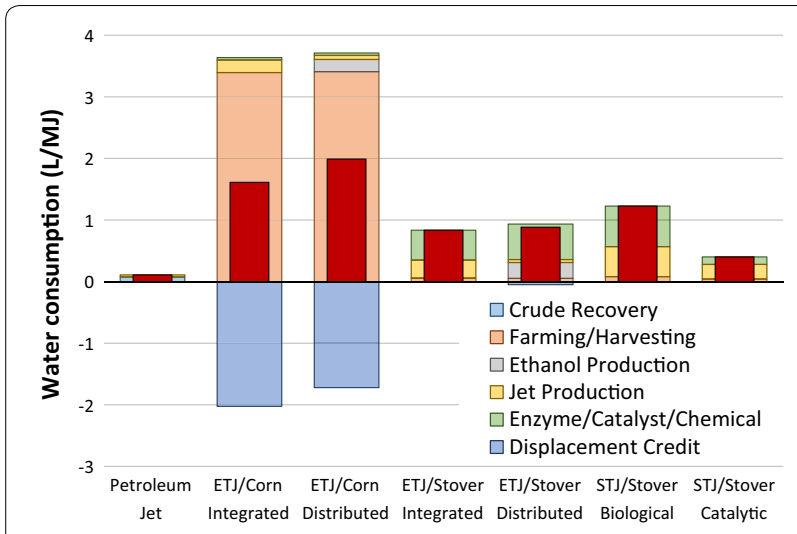

Fig. 4 WTWa water consumption of ETJ and STJ compared to petroleum jet

extraction, dry mills without $\mathrm{CO}$ extraction, and wet mills. Ethanol from dry mills with $\mathrm{CO}$ extraction, dry mills without $\mathrm{CO}$ extraction, and wet mills accounts for 71,18 , and $11 \%$ of US ethanol production, respectively [36]. Figure 5 presents the WTWa GHG emissions of ETJ with distributed plants using ethanol from dry mills with and without $\mathrm{CO}$ extraction as compared to ETJ using the US average ethanol. ETJ using ethanol from dry mills with and without $\mathrm{CO}$ extraction generates 75 and $75 \mathrm{~g} \mathrm{CO}_{2} \mathrm{e}$ of GHG emission per MJ of ETJ, respectively. Because of the small amount of $\mathrm{CO}$ relative to ethanol, the impact of CO extraction on the ETJ's GHG emissions is minimal with a process-based approach to handle the co-products $\left(0.2 \mathrm{~g} \mathrm{CO}_{2} \mathrm{e} / \mathrm{MJ}\right)$. Note that the impact of $\mathrm{CO}$ extraction would be also small with an allocation method due to the small amount of $\mathrm{CO}$ as discussed in Wang et al. [36]. Note that ETJ using ethanol from wet mills is not presented because the share of energy- and GHG-intensive wet milling ethanol plants is small.

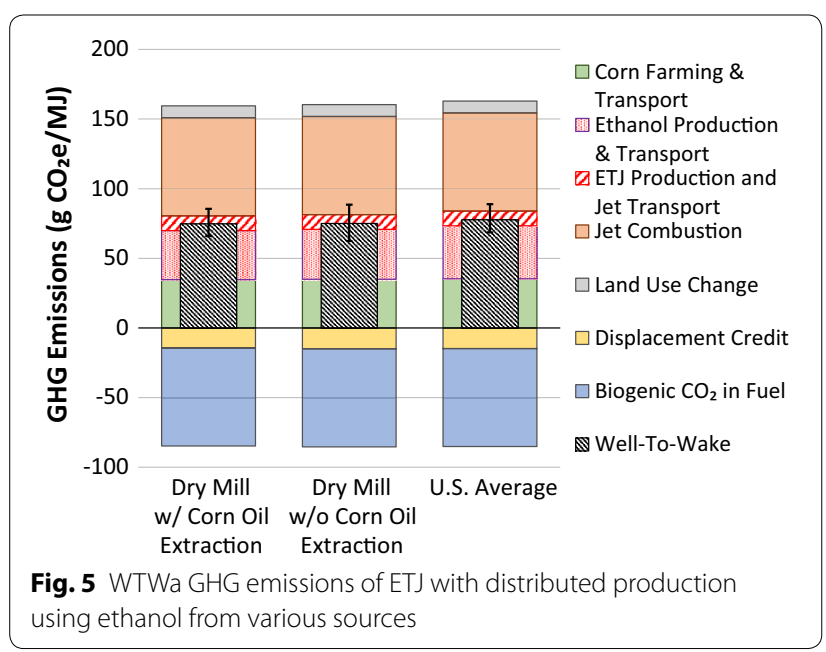

\section{Impact of $\mathrm{H}_{2}$ source on WTWa GHG emissions of STJ} via catalytic conversion

Because of the large quantity of $\mathrm{H}_{2}$ consumption in STJ production via catalytic conversion, the $\mathrm{H}_{2}$ source affects the WTWa GHG emissions of STJ significantly. Thus, this study examined the impact of three different $\mathrm{H}_{2}$ sources on the WTWa GHG emissions based on the assumptions shown in Table 4 [32]: external $\mathrm{H}_{2}$ from NG SMR, in situ $\mathrm{H}_{2}$ from biomass, and $\mathrm{H}_{2}$ from biomass gasification. As shown in Fig. 6, the WTWa GHG emissions of STJ via catalytic conversion are estimated at 61,35 , and $25 \mathrm{~g} \mathrm{CO}_{2} \mathrm{e} / \mathrm{MJ}$ with external $\mathrm{H}_{2}$ from NG SMR, in situ $\mathrm{H}_{2}$ from biomass, and $\mathrm{H}_{2}$ from biomass gasification, respectively. $\mathrm{H}_{2}$ used in the external $\mathrm{H}_{2}$ case accounts for more than $80 \%$ of the WTWa GHG emissions $\left(49 \mathrm{~g} \mathrm{CO}_{2} \mathrm{e} /\right.$ $\mathrm{MJ})$. Because a significant source of GHG emissions is removed using biomass as a $\mathrm{H}_{2}$ source, the in situ $\mathrm{H}_{2}$ and biomass gasification cases can show significantly reduced GHG emissions. The use of biomass for $\mathrm{H}_{2}$ production, however, lowers the jet fuel yields from $251 \mathrm{~L} /$ ton corn stover to $145 \mathrm{~L} /$ ton in the in situ $\mathrm{H}_{2}$ case and $157 \mathrm{~L} /$ ton in the biomass gasification case, which could adversely impact the economics of the STJ plants. Especially, the low NG price due to expansion of shale gas production in the US makes it not attractive to justify the production of $\mathrm{H}_{2}$ from biomass over NG SMR. Thus, the tradeoff between the GHG emissions and economic feasibility depending on the $\mathrm{H}_{2}$ source needs to be examined.

\section{Impact of co-product handling method on WTWa GHG emissions of corn stover-based ETJ and STJ}

As mentioned earlier, the co-product handling method is an important factor in biofuel LCA because biofuel production is associated with various co-products [35]. Thus, this study examined the impact of co-product handling method on the WTWa GHG emissions of corn

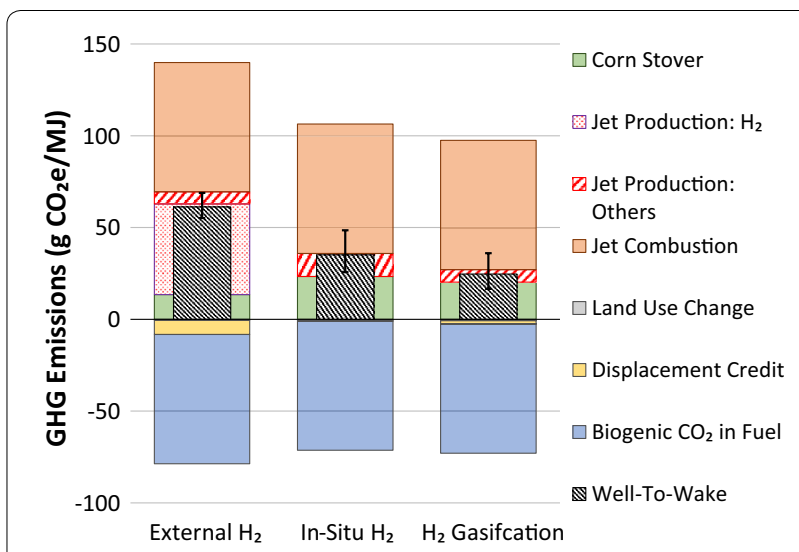

Fig. 6 WTWa GHG emissions of STJ via catalytic conversion using $\mathrm{H}_{2}$ from three different sources 
stover-based ETJ and STJ (where electricity is the coproduct), which is presented in Fig. 7. The WTWa GHG emissions of corn stover-based ETJ and STJ estimated with the displacement method are generally lower than those estimated with the energy allocation method, by 11 , 10, and $5 \mathrm{~g} \mathrm{CO}_{2} \mathrm{e} / \mathrm{MJ}$ for ETJ and STJs via biological and catalytic conversions, respectively. GHG emissions are lower when the displacement method is used, because electricity displacement credits that ethanol receives exceed the GHG emissions allocated to the electricity when the energy allocation method is used. It should be noted that the US average electricity, whose GHG intensity is estimated at $613 \mathrm{~g} \mathrm{CO}_{2} \mathrm{e} / \mathrm{kWh}$, is assumed to be displaced. If a different generation mix for electricity is assumed, the displacement credit would be changed, resulting in different WTWa GHG emissions results. For example, if electricity produced in the Midwest Reliability Organization region (covering all of Minnesota, North Dakota, and Nebraska; portions of Montana, South Dakota, Iowa, and Wisconsin; and the Upper Peninsula of Michigan), which has a GHG intensity of $714 \mathrm{~g} \mathrm{CO}_{2} \mathrm{e} /$ $\mathrm{kWh}$, were displaced, WTWa GHG emissions of corn stover-based ETJ and STJ estimated with the displacement method would increase by 2.4, 2.3, and $1.3 \mathrm{~g} \mathrm{CO}_{2} \mathrm{e} /$ MJ, respectively.

As mentioned in "WTWa analysis system boundary and methods" section, both displacement and energy allocation methods are widely used to handle electricity co-products. As evidenced by the overlaps of p10-p90 ranges in these corn stover-based ETJ and STJ pathways between the methods, both methods provide acceptable estimates on WTWa GHG emissions. In these pathways, the WTW GHG emissions estimated by a displacement method are reliable because the main product

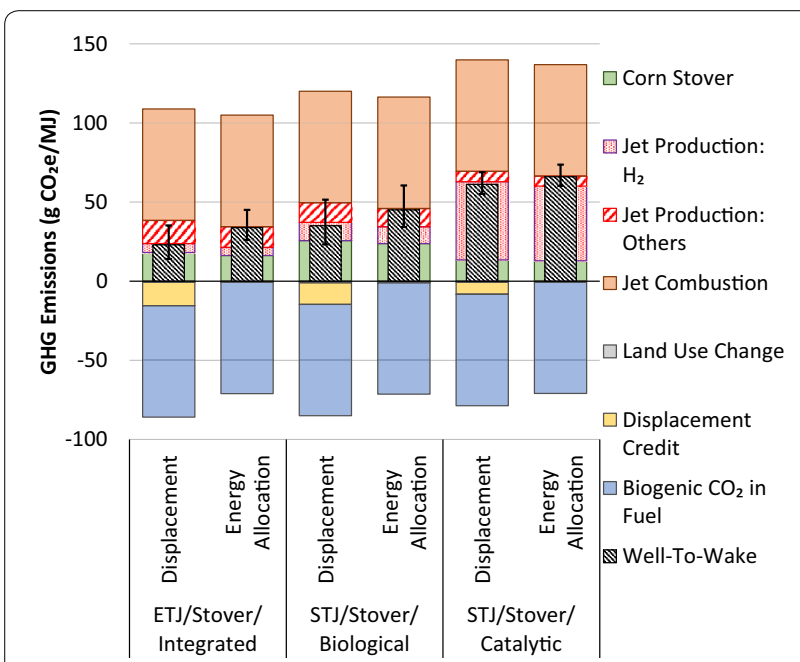

Fig. 7 WTWa GHG emissions of corn stover-based ETJ and STJ using displacement and energy allocation methods (hydrocarbon fuels) dominates the product slate and a conventional product to be displaced can be defined clearly. In case of jet production from a specific plant, the estimates can be further refined by using the regional electricity that is actually displaced with the co-produced electricity.

\section{Sensitivity analysis on key parameters of the ETJ and STJ pathways}

In addition to the error bars in Figs. 2, 3 and 5, 6, 7 presenting the aggregated impacts of the variations and uncertainties associated with the pathways using the GREET stochastic modeling feature, this study conducts a sensitivity analysis to show the impacts of individual parameters on the WTWa results of these pathways. For the sensitivity analysis, the p10 and p 90 values of key parameters in corn farming, corn ethanol production, corn stover collection, and corn stover ethanol production shown in Additional file 1: Table A1 were used. As mentioned in "Corn farming, corn stover collection, and ethanol production" section, LUC-related GHG emissions ranges estimated by Qin et al. [42] were also examined. Due to lack of reliable range estimates, this study perturbed the other key parameters by $\pm 10 \%$ to conduct the sensitivity analysis. The other key parameters include irrigation in corn farming, water use in corn and corn stover ethanol production, jet fuel, and electricity yield in jet production, and usage intensities of $\mathrm{NG}, \mathrm{H}_{2}$, electricity, yeast, enzyme/chemical, catalyst, and water in jet production.

Note that changing one parameter could affect other parameters. For example, increasing jet yield in jet production could require additional energy and $\mathrm{H}_{2}$ uses and lowers co-product yields, which require a process engineering analysis or TEA. Since this sensitivity analysis is intended to present the individual impact of each parameter rather than assessing the sensitivity of a different scenario, this sensitivity analysis treats the perturbation of each parameter independently.

Additional file 1: Figure A2 provides the sensitivity analysis results of GHG emissions on key parameters of the ETJ and STJ pathways. The values in the parenthesis for each parameter denote the values resulting in the low, base and high GHG emissions results. For all of the ETJ and STJ pathways investigated in this study, the most influential parameter is $\mathrm{N}_{2} \mathrm{O}$ conversion rate of $\mathrm{N}$ fertilizers due to the high global warming potential of $\mathrm{N}_{2} \mathrm{O}$. For the corn-based ETJ pathways, the LUC GHG emissions are also considerably important as these emissions are highly uncertain. Other important parameters to the WTWa GHG emissions include the $\mathrm{N}$ fertilizer application rate, and the jet fuel yields in jet production. 
For fossil fuel use (presented in Additional file 1: Figure A3), the jet fuel yields in jet production and the $\mathrm{N}$ fertilizer application rate are critical factors in general. Three exceptions include the corn-based ETJ pathways, the corn stover-based ETJ pathway with distributed plants, and the STJ pathway via catalytic conversion with external $\mathrm{H}_{2}$, which are sensitive to the energy use in ethanol or jet production, the electricity yield in ethanol production, and the $\mathrm{H}_{2}$ consumption in jet production, respectively.

As shown in Additional file 1: Figure A4, the water consumptions of the corn-based ETJ pathways depends largely on the irrigation in corn farming. The jet fuel yield is also important for the corn-based ETJ pathways because of the high water intensity of corn. Moreover, DGS yield in jet production in integrated plants can affect the WTWa water consumption since DGS displaces water-intensive animal feeds. On the other hand, the WTWa water consumptions of the corn stover-based ETJ and STJ pathways do not vary significantly.

\section{WTWa GHG emissions of ETJ and STJ per ton of corn stover} The WTWa GHG emissions results above are presented on a per-MJ basis, which is informative when comparing similar fuels from different sources (e.g., petroleum jet, NG-based FTJ, HEFA, and other bio-aviation fuels). These per-MJ results, however, may not address resource utilization issues, such as which pathway can bring about the greatest reduction in GHG emissions and displace the largest amount of petroleum using one ton of corn stover. As shown in "Impact of $\mathrm{H}_{2}$ source on WTWa GHG emissions of STJ via catalytic conversion" section, the two STJ cases involving catalytic conversion with internal $\mathrm{H}_{2}$ from biomass have lower GHG emissions but yield a smaller amount of liquid fuel than STJ produced via catalytic conversion with external $\mathrm{H}_{2}$ from NG SMR. Because of the low liquid fuel yields, the pathway with lower GHG emissions on a per-MJ basis could have higher GHG emissions on a per-ton-of-biomass basis.

To address this resource utilization issue, Fig. 8 presents the WTWa GHG emissions and petroleum savings of corn stover-based ETJ and STJ in $\mathrm{kg} \mathrm{CO}_{2} \mathrm{e}$ and GJ per dry ton corn stover, respectively. WTWa GHG emissions savings of ETJ, STJ via biological conversion, and STJ via catalytic conversion using external $\mathrm{H}_{2}$, in situ $\mathrm{H}_{2}$, and $\mathrm{H}_{2}$ from biomass gasification are 320, 223, 200, 244 , and $339 \mathrm{~kg} \mathrm{CO}_{2} \mathrm{e} /$ dry ton corn stover, respectively, while the WTWa petroleum savings are 5.8, 3.9, 8.1, 4.4, and $5.2 \mathrm{GJ} /$ ton, respectively. The largest GHG emissions and petroleum savings result from the displaced hydrocarbon fuels (jet, gasoline, and diesel). The savings from displaced hydrocarbon fuels include the avoided energy use and emissions associated with both production and

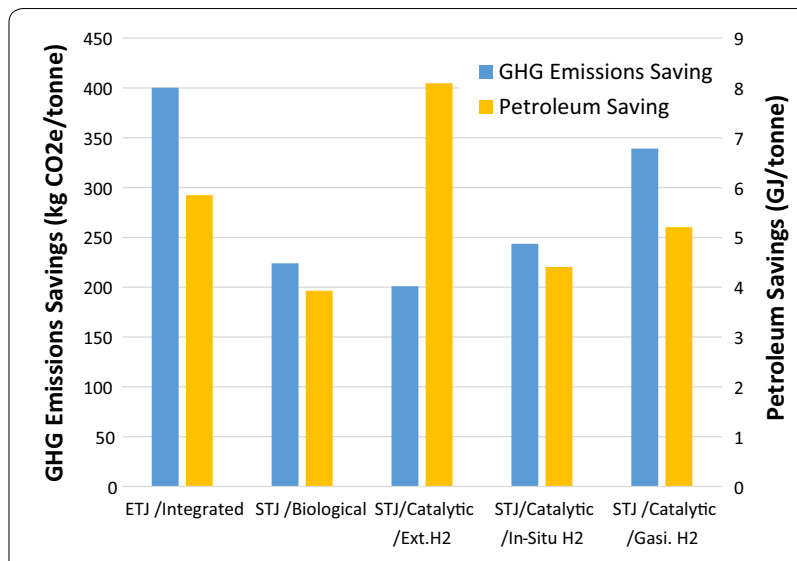

Fig. 8 WTWa GHG emissions savings and petroleum savings of corn stover-based ETJ and STJ

use of the displaced hydrocarbon fuels. Except for STJ produced via catalytic conversion with external $\mathrm{H}_{2}$, the GHG emissions and petroleum savings are directionally correlated. However, STJ produced via catalytic conversion with external $\mathrm{H}_{2}$ shows very large petroleum savings because of its high liquid fuel yield, but shows small GHG emissions savings because of its large $\mathrm{H}_{2}$ consumption. Thus, a trade-off between GHG emissions and petroleum savings exists for STJ produced via catalytic conversion with different $\mathrm{H}_{2}$ sources.

\section{Conclusions}

This study examined various emerging AJF pathways (e.g., ETJ and STJs produced via biological and catalytic conversions) and showed that the WTWa GHG emissions reductions achieved with corn stover-based ETJ with integrated production could be $73 \%$ relative to petroleum jet. For corn-based ETJ with integrated production, on the other hand, the GHG emissions are reduced by $16 \%$ relative to petroleum jet. Moreover, corn- and corn stover-based ETJ with integrated production could reduce the fossil fuel use by 35 and $77 \%$, respectively. However, ETJ consumes a much larger amount of water than petroleum jet due to irrigation for corn farming and enzyme production for corn stoverbased ETJ production, resulting in the water consumption at 1.6-1.9 L/MJ of corn-based ETJ and 0.83-0.88 L/ MJ of corn stover-based ETJ. It should be noted that ETJ offers unique opportunities to exploit extensive existing corn ethanol plants and infrastructure, and to provide a boost to staggering ethanol demand, which is largely being used as gasoline blendstock.

This study also showed that STJ synthesized via biological conversion could reduce GHG emissions by $59 \%$ 
relative to petroleum jet. On the other hand, the GHG emission reduction achieved with STJ synthesized via catalytic conversion depends highly on the $\mathrm{H}_{2}$ source. The GHG emissions of STJ synthesized via catalytic conversion can be reduced up to $71 \%$ relative to petroleum jet with $\mathrm{H}_{2}$ from biomass gasification while external $\mathrm{H}_{2}$ from NG SMR would result in 28\% WTWa GHG emissions reduction relative to petroleum jet. However, the external $\mathrm{H}_{2}$ case results in a much higher liquid fuel yield. Thus, there is a clear trade-off between GHG emissions and petroleum savings when the pathways are compared on a per-ton-of-corn stover basis. The fossil fuel use of STJ via biological and catalytic conversion with external $\mathrm{H}_{2}$ is 61 and $17 \%$ lower than that of petroleum jet, respectively, while their water consumption is estimated at 1.23 and $0.40 \mathrm{~L} / \mathrm{MJ}$, respectively.

Since the co-product handling method is a critical LCA issue, this study examined the impacts of co-product handling methods (i.e., displacement and energy allocation methods) on WTWa GHG emissions of corn stover-based ETJ and STJ, and showed that the choice of co-product handling method can change the WTWa GHG emission results by up to $11 \mathrm{~g} \mathrm{CO}_{2} \mathrm{e} / \mathrm{MJ}$. Thus, careful consideration of the co-product handling method is warranted in examining or comparing different AJF pathways. Also, this study investigated only STJ processes that combust all lignin and co-produce electricity. Lignin, however, could be converted to chemicals including adipic acid, butadiene, butanediol, and cyclohexane to improve process economics [31]. In such cases, further examination of co-product treatment is needed.

\section{Additional file}

Additional file 1. Additional file 1 includes a summary of key LUC-related emissions results from previous studies (Figure A1), the distribution function definition of 27 key parameters for the ETJ and STJ pathways (Table A1), and the sensitivity analysis results of key parameters for the ETJ and STJ pathways (Figures A2 to A4).

\begin{abstract}
Abbreviations
AJF: alternative jet fuel; GHG: greenhouse gas; WTWa: well-to-wake; ETJ: ethanol-to-jet; STJ: sugar-to-jet; HEFA: hydroprocessed ester and fatty acids; FTJ: Fischer-Tropsch jet; ATJ: alcohol-to-jet; HRJ: hydroprocessed renewable jet; NG: natural gas; ASTM: American Society for Testing and Materials; LUC: land use change; LCA: life-cycle analysis; TEA: techno-economic analysis; DGS: distillers' grains with solubles; PTWa: pump-to-wake; CO: corn oil; SMR: steam methane reforming; USDA: US Department of Agriculture.
\end{abstract}

\footnotetext{
Authors' contributions

$\mathrm{JH}$ participated in study design, collected and processed the data, conducted well-to-wake analysis, analyzed the results, and drafted the manuscript. LT conducted techno-economic analysis of ethanol-to-jet pathways, generated process engineering results of sugar-to-jet via biological conversion, and reviewed the manuscript. MW participated in study design, guided the direction of the study, and reviewed the manuscript. All authors read and approved the final manuscript.
}

\section{Author details}

${ }^{1}$ Systems Assessment Group, Energy Systems Division, Argonne National Laboratory, 9700 S. Cass Avenue, Argonne, IL 60439, USA. ${ }^{2}$ National Renewable Energy Laboratory, 15013 Denver West Parkway, Golden, CO 80401, USA.

\section{Acknowledgements}

The authors would like to thank Zia Haq, Kristen Johnson, and Alicia Lindauer of that office for their support of this study. We gratefully acknowledge the support and technical inputs from Jennifer Dunn, Zhangcai Qin, and Rui

Chen of Argonne National Laboratory, and Ryan Davis of National Renewable Energy Laboratory.

\section{Competing interests}

The authors declare that they have no competing interests.

\section{Availability of supporting data}

The datasets during and/or analyzed during the current study available from the corresponding author on reasonable request.

\section{Funding}

This study was supported by the Biomass Energy Technology Office in the US Department of Energy's Office of Energy Efficiency and Renewable Energy, under Contract DE-AC02-06CH11357.

Received: 20 August 2016 Accepted: 5 January 2017

Published online: 24 January 2017

\section{References}

1. US EIA. Annual energy outlook 2016. Washington, DC: US Energy Information Administration; 2016. Report no.: DOE/EIA-0383(2016).

2. US EPA. Inventory of US Greenhouse gas emissions and sinks: 1990-2014. Washington, DC: US EPA; 2016. Report no.: EPA 430-R-16-002.

3. US EIA. International energy statistics. 2016 [cited 2016 Jul 5]. http://www. eia.gov/countries/data.cfm.

4. International Air Transport Association. IATA sustainable aviation fuel roadmap. Geneva, Switzerland: International Air Transport Association; 2015. https://www.iata.org/whatwedo/environment/Documents/safr-12015.pdf.

5. US GAO. Observations on DOD's investments in alternative fuels. Washington, DC: US Government Accountability Office; 2015 Jul. Report no: GAO-15-674.

6. Blakeley K. DOD alternative fuels: policy, initiatives and legislative activity. Washington, DC: Congressional Research Service; 2012. Report no.: R42859.

7. Rumizen M. Sustainable alternative jet fuel certification and qualification. CAAFI biennial general Meeting 2016. Washington, DC, 25-27 Oct 2016.

8. Shonnard DR, Williams L, Kalnes TN. Camelina-derived jet fuel and diesel: sustainable advanced biofuels. Environ Prog Sustain Energy. 2010;29:382-92.

9. Fan J, Shonnard DR, Kalnes TN, Johnsen PB, Rao S. A life cycle assessment of pennycress (Thlaspi arvense L.) -derived jet fuel and diesel. Biomass Bioenergy. 2013;55:87-100.

10. Ukaew S, Beck E, Archer DW, Shonnard DR. Estimation of soil carbon change from rotation cropping of rapeseed with wheat in the hydrotreated renewable jet life cycle. Int I Life Cycle Assess. 2015;20:608-22.

11. Ukaew S, Shi R, Lee JH, Archer DW, Pearlson M, Lewis KC, et al. Full chain life cycle assessment of greenhouse gases and energy demand for canola-derived jet fuel in North Dakota, United States. ACS Sustain Chem Eng. 2016;4:2771-9.

12. Bailis RE, Baka JE. greenhouse gas emissions and land use change from Jatropha Curcas-based jet fuel in Brazil. Environ Sci Technol. 2010;44:8684-91

13. Seber G, Malina R, Pearlson MN, Olcay H, Hileman JI, Barrett SRH. Environmental and economic assessment of producing hydroprocessed jet and diesel fuel from waste oils and tallow. Biomass Bioenergy. 2014;67:108-18. 
14. Li X, Mupondwa E. Life cycle assessment of camelina oil derived biodiesel and jet fuel in the Canadian Prairies. Sci Total Environ. 2014;481:17-26.

15. Lokesh K, Sethi V, Nikolaidis T, Goodger E, Nalianda D. Life cycle greenhouse gas analysis of biojet fuels with a technical investigation into their impact on jet engine performance. Biomass Bioenergy. 2015;77:26-44.

16. Connelly EB, Colosi LM, Clarens AF, Lambert JH. Life cycle assessment of biofuels from algae hydrothermal liquefaction: the upstream and downstream factors affecting regulatory compliance. Energy Fuels. 2015;29:1653-61.

17. Fortier M-OP, Roberts GW, Stagg-Williams SM, Sturm BSM. Life cycle assessment of bio-jet fuel from hydrothermal liquefaction of microalgae. Appl Energy. 2014;122:73-82.

18. Skone TJ, Harrison WE. Life cycle greenhouse gas analysis of advanced jet propulsion fuels: Fischer-Tropsch based SPK-1 case study. Air Force Research Laboratory; 2011. Report no.: AFRL-RZ-WP-TR-2011-2138.

19. Crossin E. Mallee aviation biofuels life cycle assessment. Melbourne: Future Farm Industries CRC; 2013.

20. Stratton RW, Wong HM, Hileman Jl. Life cycle greenhouse gas emissions from alternative jet fuels. Cambridge: Partnersh. AiR Transp. Noise Emiss. Reduct. Mass. Inst. Technol.; 2010.

21. Stratton RW, Wong HM, Hileman Jl. Quantifying variability in life cycle greenhouse gas inventories of alternative middle distillate transportation fuels. Environ Sci Technol. 2011;45:4637-44.

22. Elgowainy A, Han J, Wang MQ, Carter N, Stratton RW, Hileman Jl, et al. Life cycle analysis of alternative aviation fuels in GREET. Argonne, IL: Argonne National Laboratory; 2012. Report no.: ANL/ESD/12-8.

23. Han J, Elgowainy A, Cai H, Wang MQ. Life-cycle analysis of bio-based aviation fuels. Bioresour Technol. 2013;150:447-56.

24. Agusdinata DB, Zhao F, lleleji K, DeLaurentis D. Life cycle assessment of potential biojet fuel production in the United States. Environ Sci Technol. 2011;45:9133-43.

25. Cox K, Renouf M, Dargan A, Turner C, Klein-Marcuschamer D. Environmental life cycle assessment (LCA) of aviation biofuel from microalgae, Pongamia pinnata, and sugarcane molasses. Biofuels Bioprod Biorefining. 2014;8:579-93.

26. Moreira M, Gurgel AC, Seabra JEA. Life cycle greenhouse gas emissions of sugar cane renewable jet fuel. Environ Sci Technol. 2014;48:14756-63.

27. Staples MD, Malina R, Olcay H, Pearlson MN, Hileman Jl, Boies A, et al. Lifecycle greenhouse gas footprint and minimum selling price of renewable diesel and jet fuel from fermentation and advanced fermentation production technologies. Energy Environ Sci. 2014 [cited 2014 Apr 7]. http://pubs.rsc.org/en/content/articlelanding/2014/ee/c3ee43655a.

28. Budsberg E, Crawford JT, Morgan H, Chin WS, Bura R, Gustafson R. Hydrocarbon bio-jet fuel from bioconversion of poplar biomass: life cycle assessment. Biotechnol Biofuels. 2016:9:170.

29. Argonne National Laboratory. Greenhouse gases, Regulated Emissions and Energy use in Transportation (GREET) model. 2016 [cited 2016 May 9]. http://greet.es.anl.gov/.

30. Wang W-C, Tao L, Markham J, Zhang Y, Tan E, Batan L, et al. Review of biojet fuel conversion technologies. Denver, CO: National Renewable Energy Laboratory; 2016 Jul. Report no.: NREL/TP-5100-66291. http://www.nrel. gov/docs/fy16osti/66291.pdf.

31. Davis R, Tao L, Tan ECD, Biddy MJ, Beckham GT, Scarlata C, et al. Process design and economics for the conversion of lignocellulosic biomass to hydrocarbons: dilute-acid and enzymatic deconstruction of biomass to sugars and biological conversion of sugars to hydrocarbons. Denver, CO: National Renewable Energy Laboratory; 2013 Oct. Report no: NREL/TP-5100-60223.

32. Davis R, Tao L, Scarlata C, Tan ECD, Ross J, Lukas J, et al. Process design and economics for the conversion of lignocellulosic biomass to hydrocarbons: dilute-acid and enzymatic deconstruction of biomass to sugars and catalytic conversion of sugars to hydrocarbons. Denver, CO: National Renewable Energy Laboratory; 2015 Mar. Report no.: NREL/ TP-5100-62498.

33. Renewable Fuels Associations. 2016 ethanol industry outlook. Washington: Renewable Fuels Association; 2016.

34. Carpenter D, Westover TL, Czernik S, Jablonski W. Biomass feedstocks for renewable fuel production: a review of the impacts of feedstock and pretreatment on the yield and product distribution of fast pyrolysis bio-oils and vapors. Green Chem. 2014;16:384-406.

35. Wang M, Huo H, Arora S. Methods of dealing with co-products of biofuels in life-cycle analysis and consequent results within the US context. Energy Policy. 2011;39:5726-36.
36. Wang Z, Dunn JB, Han J, Wang MQ. Influence of corn oil recovery on lifecycle greenhouse gas emissions of corn ethanol and corn oil biodiesel. Biotechnol Biofuels. 2015;8:178

37. Wang M, Han J, Dunn JB, Cai H, Elgowainy A. Well-to-wheels energy use and greenhouse gas emissions of ethanol from corn, sugarcane and cellulosic biomass for US use. Environ Res Lett. 2012;7:45905.

38. USDA. NASS-National Agricultural Statistics Service. 2014 [cited 2014 Jul 1]. http://www.nass.usda.gov/index.asp.

39. Mueller S, Kwik J. Corn ethanol: emerging plant energy and environmental technologies. Chicago, IL: University of Illinois at Chicago; 2013 Apr. http://ethanolrfa.3cdn.net/fe5f4b7a4bdbc12101_2gm6bejk4.pdf.

40. Lampert DJ, Cai H, Elgowainy A. Wells to wheels: water consumption for transportation fuels in the United States. Energy Environ Sci. 2016;9:787-802.

41. Searchinger T, Heimlich R, Houghton RA, Dong F, Elobeid A, Fabiosa $J$, et al. Use of US croplands for biofuels increases greenhouse gases through emissions from land-use change. Science. 2008;319:1238-40.

42. Qin Z, Dunn JB, Kwon H, Mueller S, Wander MM. Influence of spatially dependent, modeled soil carbon emission factors on life-cycle greenhouse gas emissions of corn and cellulosic ethanol. GCB Bioenergy. 2016;8:1136-49.

43. Qin Z, Canter CE, Dunn JB, Mueller S, Kwon H, Han J, et al. Incorporating agricultural management practices into the assessment of soil carbon change and life-cycle greenhouse gas emissions of corn stover ethanol production. Argonne, IL: Argonne National Laboratory; 2015 Sep. Report no.: ANL/ESD-15/26. http://www.osti.gov/scitech/biblio/1221938.

44. Humbird D, Davis R, Tao L, Kinchin C, Hsu D, Aden A, et al. Process design and economics for biochemical conversion of lignocellulosic biomass to ethanol: dilute-acid pretreatment and enzymatic hydrolysis of corn stover. Denver, CO: National Renewable Energy Laboratory; 2011 May. Report no.: NREL/TP-5100-47764.

45. Kwiatkowski JR, McAloon AJ, Taylor F, Johnston DB. Modeling the process and costs of fuel ethanol production by the corn dry-grind process. Ind Crops Prod. 2006;23:288-96

46. Wang M, Wu M, Huo H. Life-cycle energy and greenhouse gas emission impacts of different corn ethanol plant types. Environ Res Lett. 2007;2:24001.

47. Wang M, Han J, Haq Z, Tyner WE, Wu M, Elgowainy A. Energy and greenhouse gas emission effects of corn and cellulosic ethanol with technology improvements and land use changes. Biomass Bioenergy. 2011:35:1885-96

48. Dunn J, Mueller S, Wang M, Han J. Energy consumption and greenhouse gas emissions from enzyme and yeast manufacture for corn and cellulosic ethanol production. Biotechnol Lett. 2012;34:2259-63.

49. Dunn J, Mueller S, Kwon H, Wang MQ. Land-use change and greenhouse gas emissions from corn and cellulosic ethanol. Biotechnol Biofuels. 2013;6:51.

50. Canter CE, Dunn JB, Han J, Wang Z, Wang M. Policy implications of allocation methods in the life cycle analysis of integrated corn and corn stover ethanol production. BioEnergy Res. 2015;9:77-87.

51. Cai H, Brandt AR, Yeh S, Englander JG, Han J, Elgowainy A, et al. Well-towheels greenhouse gas emissions of Canadian oil sands products: implications for US petroleum fuels. Environ Sci Technol. 2015;49:8219-27. doi:10.1021/acs.est.5b01255.

52. US EIA. Annual energy outlook 2015. Washington, DC: US Energy Information Administration; 2015. Report no.: DOE/EIA-0383(2015).

53. Brandt AR, Yeskoo T, McNally MS, Vafi K, Yeh S, Cai H, et al. Energy intensity and greenhouse gas emissions from tight oil production in the bakken formation. Energy Fuels. 2016;30:9613-21.

54. Ghandi A, Yeh S, Brandt AR, Vafi K, Cai H, Wang MQ, et al. Energy intensity and greenhouse gas emissions from crude oil production in the eagle ford region: input data and analysis methods. Argonne: Argonne National Laboratory; 2015.

55. Burnham A, Han J, Clark CE, Wang M, Dunn JB, Palou-Rivera I. Life-cycle greenhouse gas emissions of shale gas, natural gas, coal, and petroleum. Env Sci Technol. 2011;46:619-27.

56. Elgowainy A, Han J, Cai H, Wang M, Forman GS, DiVita VB. Energy efficiency and greenhouse gas emission intensity of petroleum products at US refineries. Environ Sci Technol. 2014:48:7612-24.

57. ASTM. Standard specification for denatured fuel ethanol for blending with gasolines for use as automotive spark-ignition engine fuel. Conshohocken: ASTM International; 2016. 